\title{
Global incidence of suicide among Indigenous peoples: a systematic review
}

Nathaniel J. Pollock ${ }^{1,2^{*}}$ D, Kiyuri Naicker ${ }^{3}$, Alex Loro ${ }^{3}$, Shree Mulay ${ }^{1}$ and lan Colman ${ }^{3}$

\begin{abstract}
Background: Suicide is the second leading cause of death among adolescents worldwide, and is a major driver of health inequity among Indigenous people in high-income countries. However, little is known about the burden of suicide among Indigenous populations in low- and middle-income nations, and no synthesis of the global data is currently available. Our objective was to examine the global incidence of suicide among Indigenous peoples and assess disparities through comparisons with non-Indigenous populations.

Methods: We conducted a systematic review of suicide rates among Indigenous peoples worldwide and assessed disparities between Indigenous and non-Indigenous populations. We performed text word and Medical Subject Headings searches in PubMed, MEDLINE, Embase, Cumulative Index of Nursing and Allied Health (CINAHL), PsycINFO, Latin American and Caribbean Health Sciences Literature (LILACS), and Scientific Electronic Library Online (SciELO) for observational studies in any language, indexed from database inception until June 1, 2017. Eligible studies examined crude or standardized suicide rates in Indigenous populations at national, regional, or local levels, and examined rate ratios for comparisons to non-Indigenous populations.
\end{abstract}

Results: The search identified 13,736 papers and we included 99. Eligible studies examined suicide rates among Indigenous peoples in 30 countries and territories, though the majority focused on populations in high-income nations. Results showed that suicide rates are elevated in many Indigenous populations worldwide, though rate variation is common, and suicide incidence ranges from 0 to 187.5 suicide deaths per 100,000 population. We found evidence of suicide rate parity between Indigenous and non-Indigenous populations in some contexts, while elsewhere rates were more than 20 times higher among Indigenous peoples.

Conclusions: This review showed that suicide rates in Indigenous populations vary globally, and that suicide rate disparities between Indigenous and non-Indigenous populations are substantial in some settings but not universal. Including Indigenous identifiers and disaggregating national suicide mortality data by geography and ethnicity will improve the quality and relevance of evidence that informs community, clinical, and public health practice in Indigenous suicide prevention.

Keywords: Indigenous, First peoples, Inuit, Health disparities, Suicide, Mortality, Surveillance, Epidemiology

\section{Background}

Globally, suicide accounts for approximately 800,000 deaths annually [1] and is the second leading cause of mortality among adolescents [2]. According to the World Health Organization (WHO), low- and middle-income countries

\footnotetext{
* Correspondence: nathaniel.pollock@med.mun.ca

'Division of Community Health and Humanities, Faculty of Medicine, Memorial University, Prince Philip Drive, St. John's, Newfoundland and Labrador A1B 3V6, Canada

2Labrador Institute of Memorial University, P.O. Box 490, Stn. B, 219 Hamilton River Road, Happy Valley-Goose Bay, ,Newfoundland and Labrador AOP 1E0, Canada

Full list of author information is available at the end of the article
}

and high-income countries have similar annual age-standardized suicide rates at 11.2 and 12.7 per 100,000 respectively; however, low- and middle-income countries account for $75 \%$ of suicide deaths worldwide [1]. National suicide rates range from less than one to 44 per 100,000 population, though there is often a disproportionate burden among specific subgroups within countries, such as Indigenous peoples [1]. Studies from high-income countries including Australia [3, 4], New Zealand [5], the USA [6, 7], Canada [8-10], and other Arctic nations [11-14] consistently find elevated suicide rates among Indigenous

(c) The Author(s). 2018 Open Access This article is distributed under the terms of the Creative Commons Attribution 4.0 International License (http://creativecommons.org/licenses/by/4.0/), which permits unrestricted use, distribution, and 
populations, with substantial rate disparities compared to non-Indigenous populations. Several studies have shown that regional suicide rates vary greatly among Indigenous peoples, and that some Indigenous populations have low rates or no incidence of suicide $[15,16]$.

Indigenous peoples and nations differ vastly in culture, language, political autonomy, and relative wealth, yet many face similar social disadvantages and health disparities as a result of colonization [17-19]. Colonial governments have used discriminatory legislation and policies to deny rights and economic opportunities, and have attempted to acculturate Indigenous people into non-Indigenous societies [17, 19, 20]. Structural violence meted out by governments has taken many forms including dispossessing Indigenous peoples from traditional and sovereign lands, forced settlement and relocation, and outlawing cultural practices and languages [17-21]. This violence is grossly evident in the twentieth century assimilationist policies of former British colonies such as Canada and Australia. Indigenous children were systematically removed from their communities and placed in non-Indigenous institutions or families with the policy mandate to "weaken family ties and cultural linkages, and to indoctrinate children into a new culture" ([20], p. v). The contemporary legacy of this type of social engineering manifests in differential exposures to health threats and in inequitable outcomes that show up across generations $[20,22]$. Intergenerational trauma from institutionalized abuse and racism experienced by Indigenous peoples has been linked to persistent social and mental health problems in some communities [19, 20,23].

Although evidence has shown a disproportionate burden of suicide among Indigenous populations in national and regional studies, a global and systematic investigation of this topic has not been undertaken to date. Previous reviews of suicide epidemiology among Indigenous populations have tended to be less comprehensive or not systematic, and have often focused on subpopulations such as youth [24, 25], high-income countries $[9,26]$, or regions such as Oceania [27] or the Arctic $[24,28]$. Given that approximately $80 \%$ of the world's more than 300 million Indigenous people live in Asia, Latin America, and Africa [17, 18], a comprehensive study of global suicide rates that includes low- and middle-income countries is needed. Our aim was to examine the published findings on the incidence of suicide among Indigenous peoples worldwide, and to compare rates with non-Indigenous or general populations to assess relative disparities.

\section{Methods}

\section{Search strategy}

We systematically reviewed findings on the incidence of suicide in Indigenous populations worldwide. We searched for studies that analyzed population-based data on suicide deaths, and included papers that reported crude or standardized mortality rates. Health science librarians were consulted about the design of the search strategy with the aim to capture all peer-reviewed literature. The search combined terms related to three concept areas: population (Indigenous), outcome (suicide mortality rates), and study design (observational). Term selection was based on previous systematic reviews and combined key terms adapted for each database and also Medical Subject Headings $(\mathrm{MeSH})$ as applicable. The study protocol is available in Additional file 1: Supplement 1. Additional details about the methods are reported in Additional file 1: Supplement 2 , including citations for previous reviews, a list of included terms, a description of the procedures used for study selection and eligibility criteria, and a complete list of databases and hand-searched review articles.

One author (NJP) performed online text word and MeSH searches for articles indexed in PubMed, MEDLINE, Embase, Cumulative Index of Nursing and Allied Health (CINAHL), PsycINFO, Latin American and Caribbean Health Sciences Literature (LILACS), and Scientific Electronic Library Online (SCiELO). A second author (KN) replicated the search in PubMed and obtained the same number of articles as the first author. We searched for studies in any language, indexed from database inception until June 1, 2017. We conducted a secondary search with a comprehensive list of terms for specific tribal groups, nations, and populations identified in previous reviews. As no additional studies were identified, this approach validated the primary search. We also searched the WHO's regional medical literature indexes, Indigenous-specific online research portals, and journals focused on Indigenous health. We hand-searched the reference lists of included articles and previous reviews to identify other eligible studies. Additional file 1: Supplement 2 includes a list of all databases and hand-searched sources.

One author (NJP) imported the results into a reference management program and removed duplicates. Two authors (NJP and KN) read the abstracts and screened in papers if they (1) reported a population-based crude and/or standardized suicide rate, or count and population data; (2) reported a rate for an Indigenous population; and (3) used an observational design. We excluded articles that did not include an Indigenous population, focused only on a specific age, gender, clinical subgroup, or deaths from a specific cause (for example, firearms), or were not peer-reviewed. Articles were also excluded if they were iterations, program evaluations or experimental studies, not primary studies, from the gray literature, or used identical data sources as prior studies.

Although there is no international consensus on the definition of Indigenous, we used the United Nation's working definition to assess study population eligibility 
$[17,18]$. The UN's conceptualization of Indigenous involves self and group identification; a special attachment to and use of traditional land, distinct knowledge, language, and culture; distinct social, economic, and political systems; common ancestry with original territorial occupants; participation in maintenance and reproduction of distinct ethnic identity; and a non-dominant socio-political status [17, 18]. A paper was eligible based on this criterion if it reported an outcome for an Indigenous population, tribe, community, nation, or group, including papers that used the geographic proxy method. For the proxy method, census data is used to detect areas where Indigenous people are a majority population $[29,30]$. We considered an area to be a proxy identifier if $80 \%$ or more of the population self-identified as Indigenous.

Two authors reviewed the full text of each paper and assessed eligibility based on inclusion criteria. At this stage, we excluded papers that did not report rates for the majority of the population (aged 15-65 years), did not conduct the primary data analysis, or provided rates in figures only and did not report count and population data. If two eligible articles used the same data source with a period of overlap, we included the article with the longer study period. During screening, full text review, and data extraction, we resolved disagreements through discussion or consultation with a third author. Translators helped assess non-English language articles and assisted with data extraction for four included studies. The following data was independently extracted by two authors (AL and NJP), then compared: citation, study design, country and region/community, Indigenous population, data source, standard population, number of suicide deaths, population count, crude and standardized suicide rates (overall and by gender and age group), comparative rates for a non-Indigenous or general population, and the measure of relative effect (incidence rate ratio).

\section{Data analysis}

We summarized all included studies in a table and reported counts, population, crude and standardized suicide mortality rates, and rate ratios. We calculated crude suicide mortality incidence rates for articles that reported only count and population data, and we estimated rate ratios when not otherwise reported by dividing the Indigenous population rate by the comparison population rate. To identify global patterns, we presented rates and rate ratios in tables and figures grouped by WHO region, country, population, and gender; we did not pool the data due to heterogeneity. We also reported on trends in suicide mortality over time and by age group; reported time trends reflect results from included studies, not pooled and recalculated rates. We modified the Newcastle-Ottawa Scale and used it to assess the quality of included articles. Additional file 1: Supplement 2 includes a description of the quality assessment procedures and scoring, and the Preferred Reporting Items for Systematic Reviews and Meta-Analyses (PRISMA) checklist is provided in Additional file 1: Supplement 4 [31].

\section{Results}

The search identified 13,736 papers; after removing duplicates, screening abstracts, and full text review, we included 99 in our analysis (Fig. 1). Included studies examined suicide rates in Indigenous populations in 30 countries and territories across six decades (Table 1), though the majority focused on those in high-income countries such as American Indian and Alaska Natives in the USA $(n=35)$ and Inuit and First Nations in Canada $(n=14)$. Studies in low- and middle-income countries $(n=22)$ were mostly from Brazil $(n=4)$, China and Taiwan $(n=6)$, and Fiji $(n=5)$. Coverage included circumpolar Indigenous peoples such as Sámi $(n=3)$ and Nenets $(n=1)$, and populations from the Western Pacific region including Aboriginal and Torres Strait Islanders in Australia $(n=6)$ and Māori and other Pacific peoples $(n=16)$. Four studies were transnational comparisons [32-35], though numerous papers included multiple Indigenous groups within a single country. Studies were mostly of moderate quality (mean 2.79 on a 4-point scale) based on our assessment of study characteristics, as reported in Additional file 1: Supplement 3, Tables S1 and S2.

\section{Incidence}

We extracted population-based suicide mortality rates from 93 papers (Table 2) and included gender-specific incidence data from six additional studies [5, 10, 36-39]. Overall, suicide rates among Indigenous peoples varied at all levels of aggregation in both high-income and lowand middle-income countries, and spanned from zero to 187.5 deaths per 100,000 person-years (PY; Table 2). In high-income countries, national and provincial suicide rates among Indigenous peoples ranged from 1.7 per 100,000 in Brunei Darussalam [40] to 50.4 per 100,000 among Aboriginal and Torres Strait Islanders in Northern Territory, Australia [41]. Rates in high-income countries were highest among rural Indigenous populations and in sparsely populated regions such as the Arctic. Among low- and middle-income countries, Palawan communities in the Philippines had the highest crude suicide rates (134 per 100,000) [42], while Indigenous peoples in Malaysia [43] and some Pacific small island states such as Fiji had crude rates under 7 per 100,000 population. The number of suicide deaths used for rate calculations ranged from zero to 4219 (Table 2). 


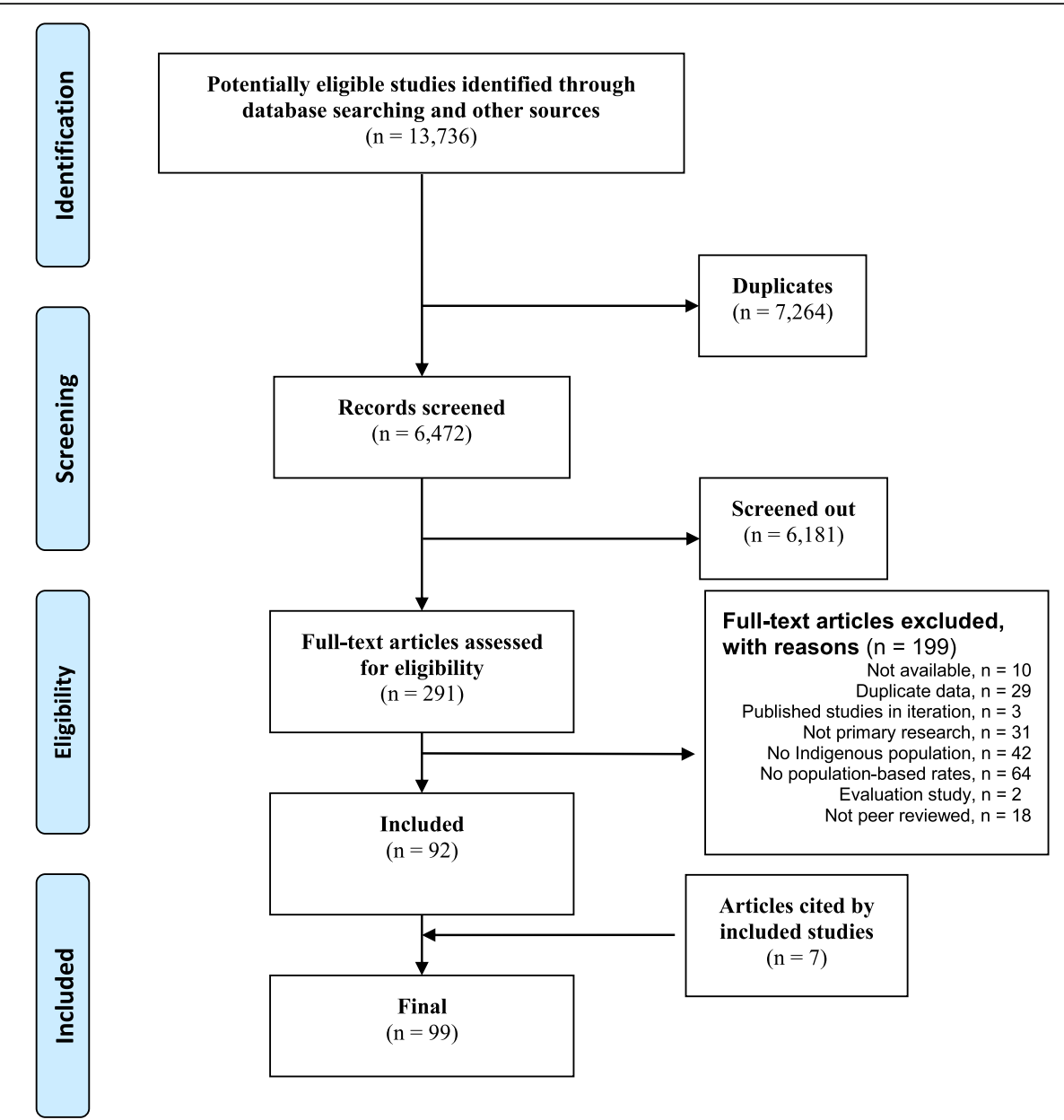

Fig. 1 Flow diagram of study selection

\section{Measure of relative effect}

Incidence rate ratios were reported or calculated for 102 Indigenous populations in 69 studies. The results showed rate disparities in the majority of studies (Fig. 2), though 22 reported rate ratios below one. The rate ratios ranged from 0.04 in China [44] to more than 20 in Brazil [45] and Canada [30] (Additional file 1: Supplement 3, Table S4). Most Indigenous populations had higher suicide rates than comparison groups; disparities were widest in studies with small populations. One study reported a suicide rate of zero for an urban Indigenous population in Brazil compared the general population rate of 4.8 per 100,000 in the same city [46].

\section{Time trends}

Suicide rates appeared to increase over time, especially in the latter half of the twentieth century, though reports were limited. Among studies with reported time series $(n=24)$, most $(83 \%, n=20)$ had fewer than 10 data points and covered an average of
19 years. A study in Greenland was the exception; it reported longitudinal data that showed a steady suicide rate increase among Inuit that began with the near absence of suicide in the early part of the twentieth century $(2.4$ per 100,000$)$ and climbed exponentially to a rate of 110.4 per 100,000 in 2010-2011; the average number of suicides per year changed from less than one to 55 during this period [12]. Aboriginal and Torres Strait Islanders in Northern Territory, Australia experienced similar rate accelerations (6.1 per 100,000 in 1981 to 50.4 per 100,000 in 2002) [41], while incidence among Alaska Natives was relatively stable, though high, from the 1980s to the early 2000s [47, 48]. Indigenous peoples in the Micronesian islands experienced a sixfold increase in suicide rates between the 1960s and the late 1980s (from 4.3 to 25.8 per 100,000 ) [35], and one study reported slight rate declines for both Māori and non-Māori in New Zealand from 1996 to 2002 [5]. Annual rates tended to fluctuate in studies with small populations. 
Table 1 Overview of included studies

\begin{tabular}{|c|c|c|}
\hline & $\begin{array}{l}\text { No. of studies } \\
(N)\end{array}$ & $\begin{array}{l}\% \text { of total } \\
(n / 99)\end{array}$ \\
\hline \multicolumn{3}{|l|}{ Decade of publication } \\
\hline 1960-1979 & 12 & $12.1 \%$ \\
\hline $1980 s$ & 23 & $23.2 \%$ \\
\hline $1990 \mathrm{~s}$ & 25 & $25.3 \%$ \\
\hline $2000 s$ & 17 & $17.2 \%$ \\
\hline $2010 s$ & 22 & $22.2 \%$ \\
\hline \multicolumn{3}{|l|}{ World Bank income } \\
\hline High-income & 76 & $76.8 \%$ \\
\hline Low- and middle-income & 22 & $22.2 \%$ \\
\hline Multiple & 1 & $1.0 \%$ \\
\hline \multicolumn{3}{|l|}{ WHO Region } \\
\hline Western Pacific & 33 & $33.3 \%$ \\
\hline European & 8 & $8.1 \%$ \\
\hline Region of the Americas & 56 & $56.6 \%$ \\
\hline Multiple regions & 2 & $2.0 \%$ \\
\hline \multicolumn{3}{|l|}{ Total Indigenous population } \\
\hline Less than 10,000 & 17 & $17.2 \%$ \\
\hline $10,000-99,999$ & 32 & $32.3 \%$ \\
\hline $100,000-999,999$ & 12 & $12.1 \%$ \\
\hline $1,000,000+$ & 4 & $4.0 \%$ \\
\hline Not reported & 34 & $34.3 \%$ \\
\hline \multicolumn{3}{|c|}{ Number of suicide deaths among Indigenous population } \\
\hline Less than 20 & 18 & $18.2 \%$ \\
\hline $21-99$ & 23 & $23.2 \%$ \\
\hline 100-999 & 23 & $23.2 \%$ \\
\hline $1000+$ & 4 & $4.0 \%$ \\
\hline Not reported & 31 & $31.3 \%$ \\
\hline
\end{tabular}

\section{Age differences}

Age-specific rates were reported in 39 studies; various age categories were used, and rates were often only available for select strata. Youth less than 30 years old, especially those aged 15-24 years old, had the highest suicide rates of any age group in $89 \%$ of studies $(n=34)$ that reported age-specific rates. In the larger studies (> 100 total suicides) with age-specific incidence, youth suicide rates ranged from 15.9 to 108 per 100,000 population. Very few studies reported deaths or rate estimates for adults more than 60 years old.

\section{Gender differences}

Men accounted for the majority of suicide deaths in all but four studies; only two of these four studies reported a greater number of suicide deaths among women $[49,50]$. Studies with gender-specific crude and age-standardized rates $(n=35)$ ranged from zero to 75.5 per 100,000 among
Indigenous women (Additional file 1: Supplement 3, Table S3). Suicide rates were higher among Indigenous men compared to Indigenous women, though rate differences were marginal among some Pacific populations [33, 51]. Suicide rates were also higher among Indigenous men than for men in comparison populations in all countries except Israel and Fiji. Outside of the relatively low rates among Indigenous men in these countries, estimates ranged from 19.5 among Sámi [13] to 248.7 per 100,000 among Inuit [30].

\section{Discussion}

This study showed that the rate of suicide is elevated in many Indigenous populations globally, but that rate variation is common (Fig. 1). The evidence of substantial rate disparities for Indigenous peoples in Australia, Brazil, Taiwan, and circumpolar countries is notable. Equally important, we found that disparities were marginal or non-existent in some US territories and Pacific nations; we also identified 21 studies in which Indigenous populations had lower suicide rates than non-Indigenous populations. These results demonstrate that the high incidence of suicide and large rate disparities are not universal among Indigenous peoples. This confirms and extends findings from prior research that reported variation in localized estimates in the USA [52] and Canada [16].

Worldwide variation in the incidence of suicide among Indigenous peoples has complex and place-based social origins. These origins are traceable to regional differences in the impact of colonization, which is widely recognized as a major determinant of Indigenous health [17-19, 53]. Colonial governments have historically threatened the well-being of Indigenous peoples through chronic and often state-sanctioned discrimination and human rights abuses, and continue to do so in many countries [18, 20,23]. Until 2016, several high-income countries had not ratified the United Nations Declaration on the Rights of Indigenous Peoples, and therefore legislative reforms to recognize Indigenous self-determination lagged. As a result, many Indigenous nations have yet to attain political sovereignty over lands and natural resources, education, or health care.

Globally, Indigenous peoples commonly experience social and economic marginalization and, as a consequence, some of the most disparate health outcomes $[17,18,53]$. In this context, the extent and the persistence of high suicide rates and rate disparities reveal a striking deficit in the global effort to prevent suicide and achieve social and health equity. This is further challenged by overlapping barriers to accessing health care and community supports, especially in rural areas and low- and middle-income countries. Barriers include fragmented care networks, lack of access to services due to geography, discriminatory attitudes from health care providers, and services that are not culturally safe or provided in the necessary language $[18,54,55]$. In resource- 


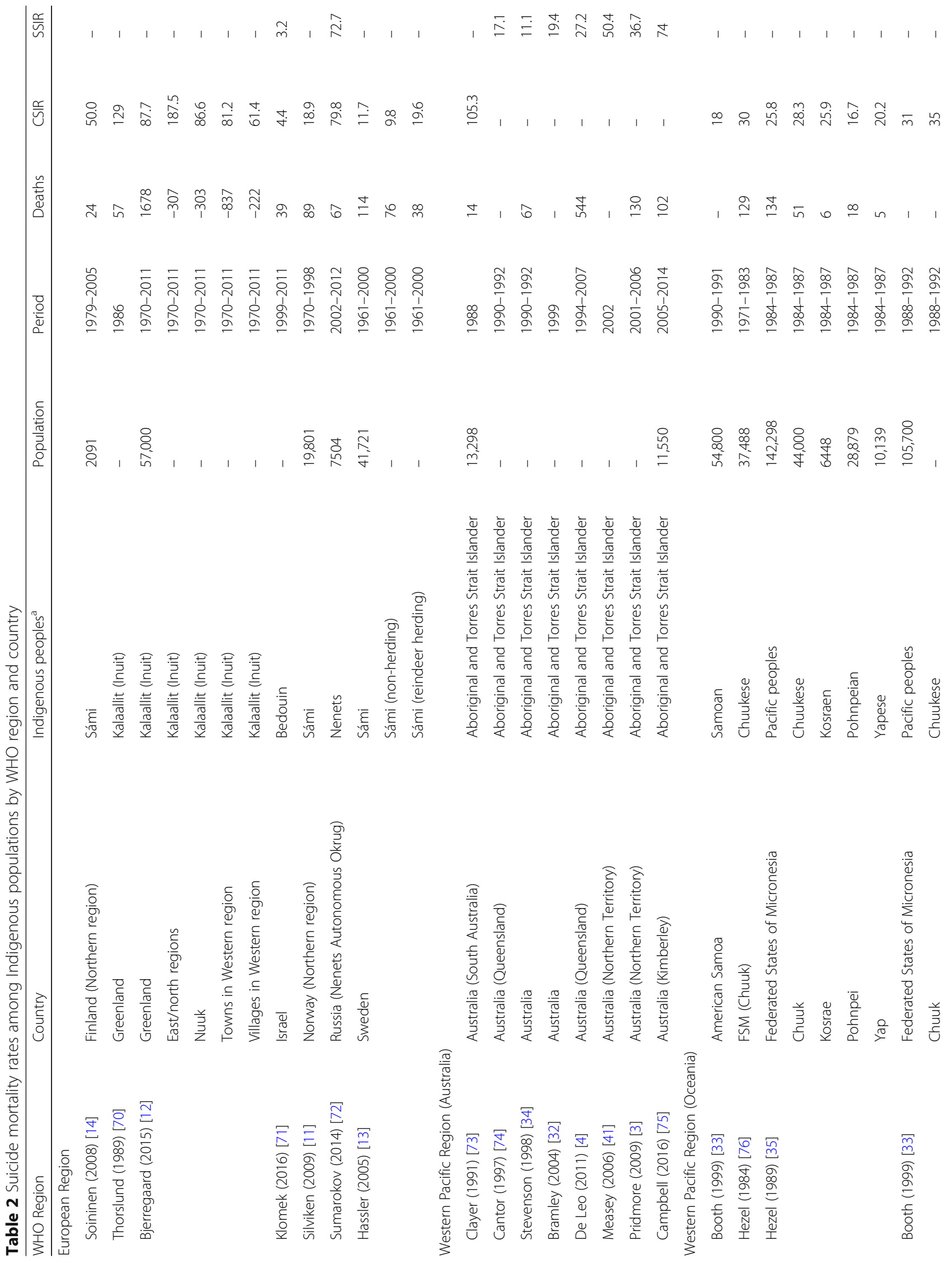




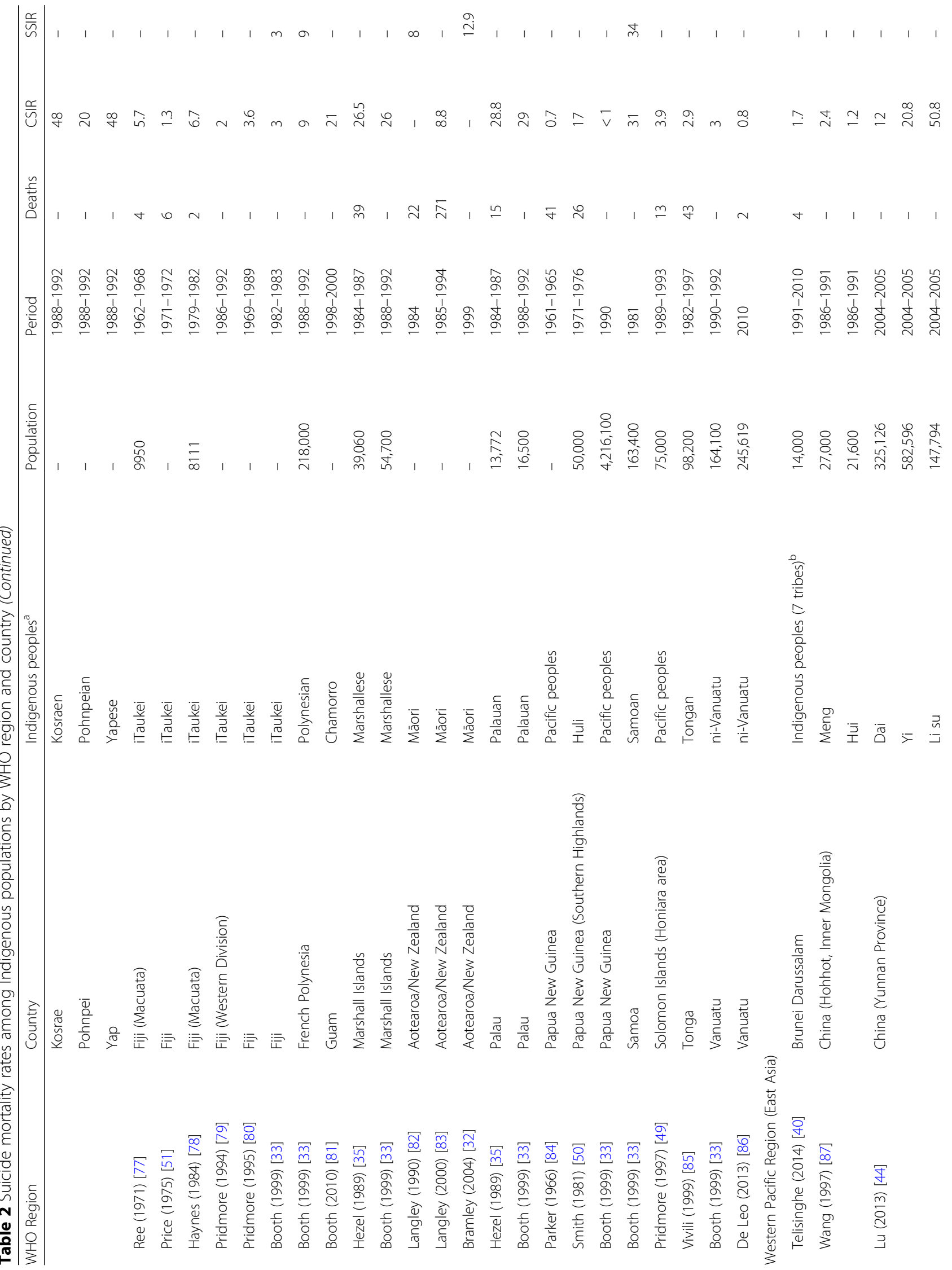




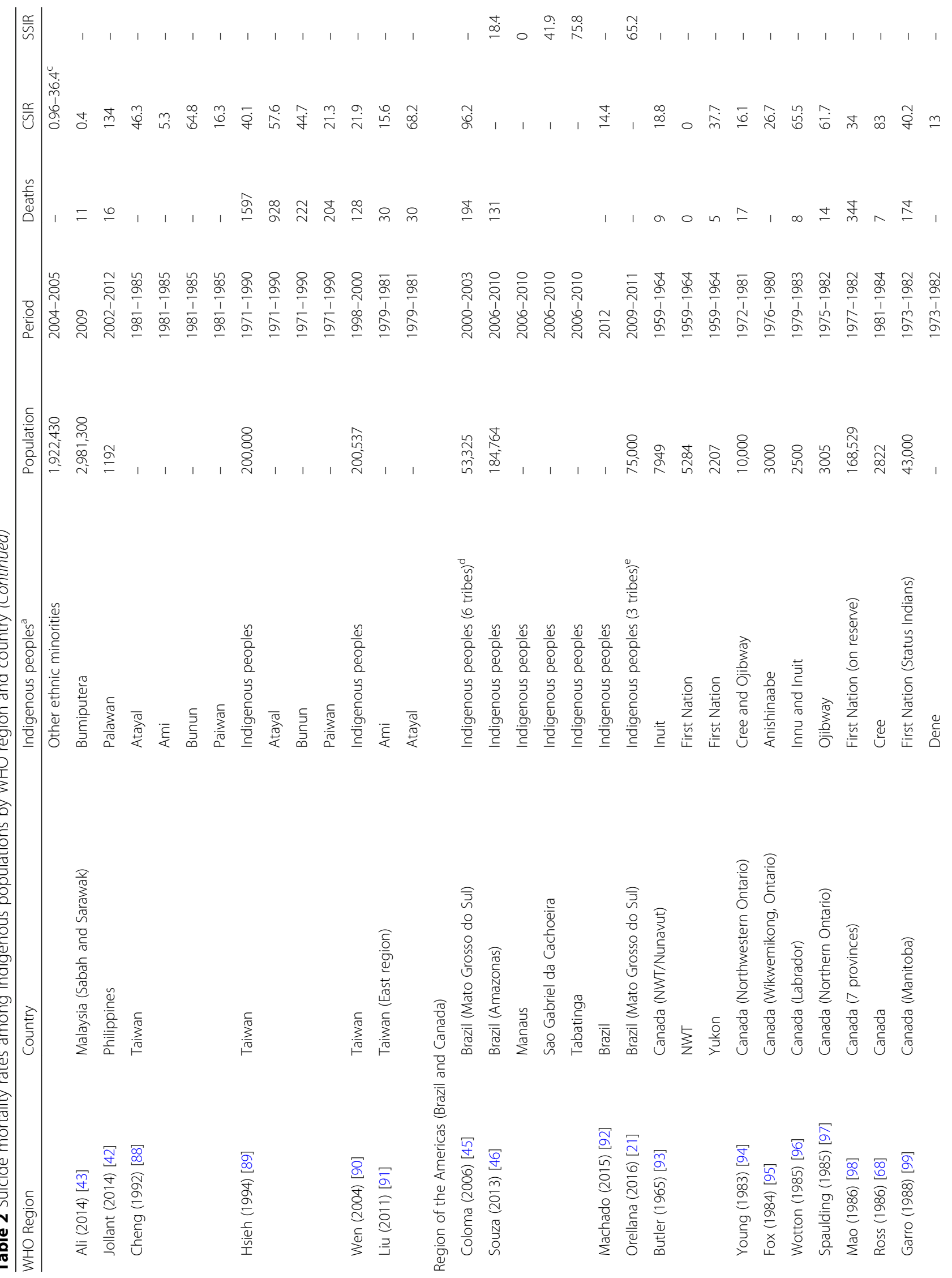




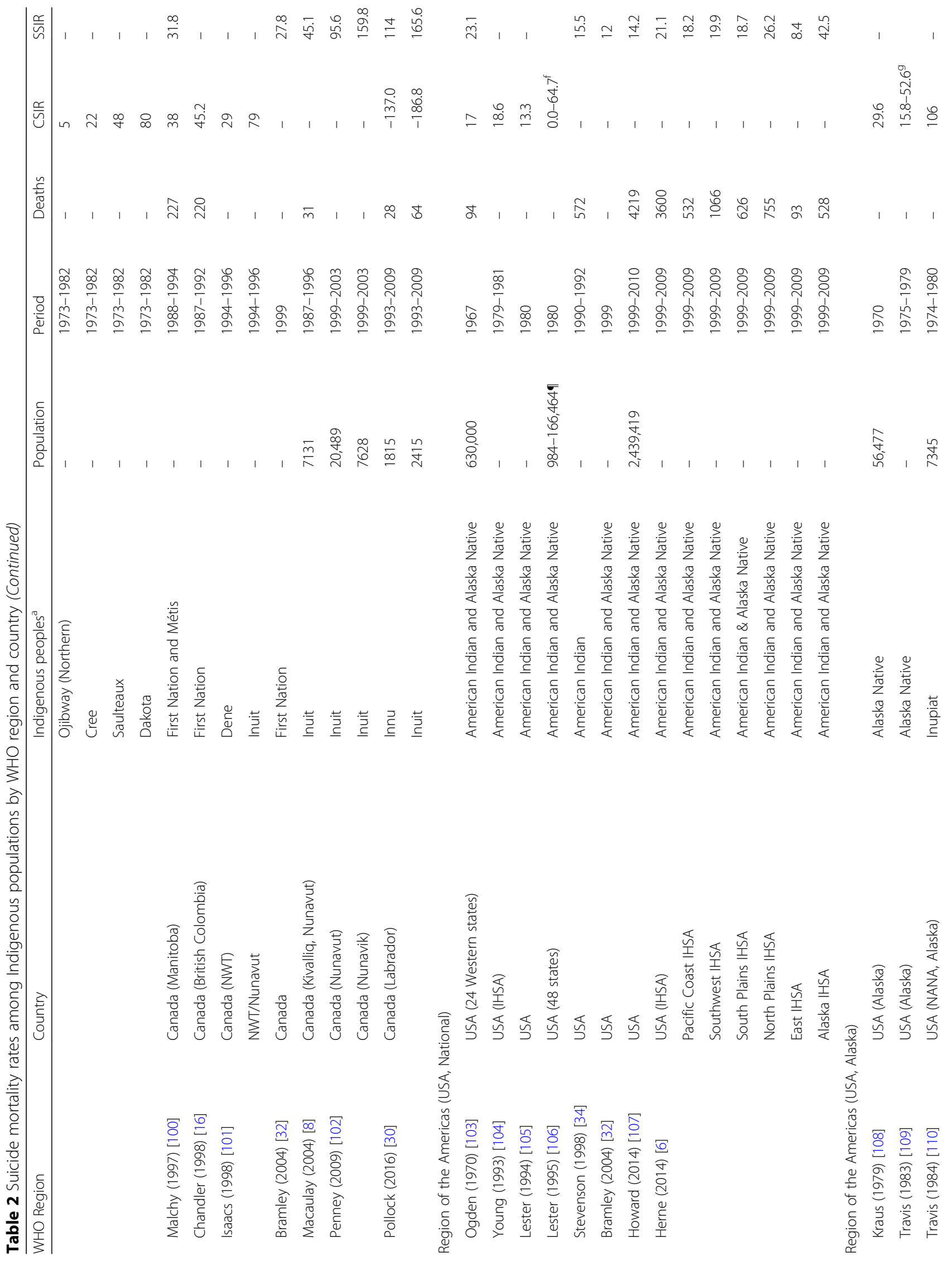




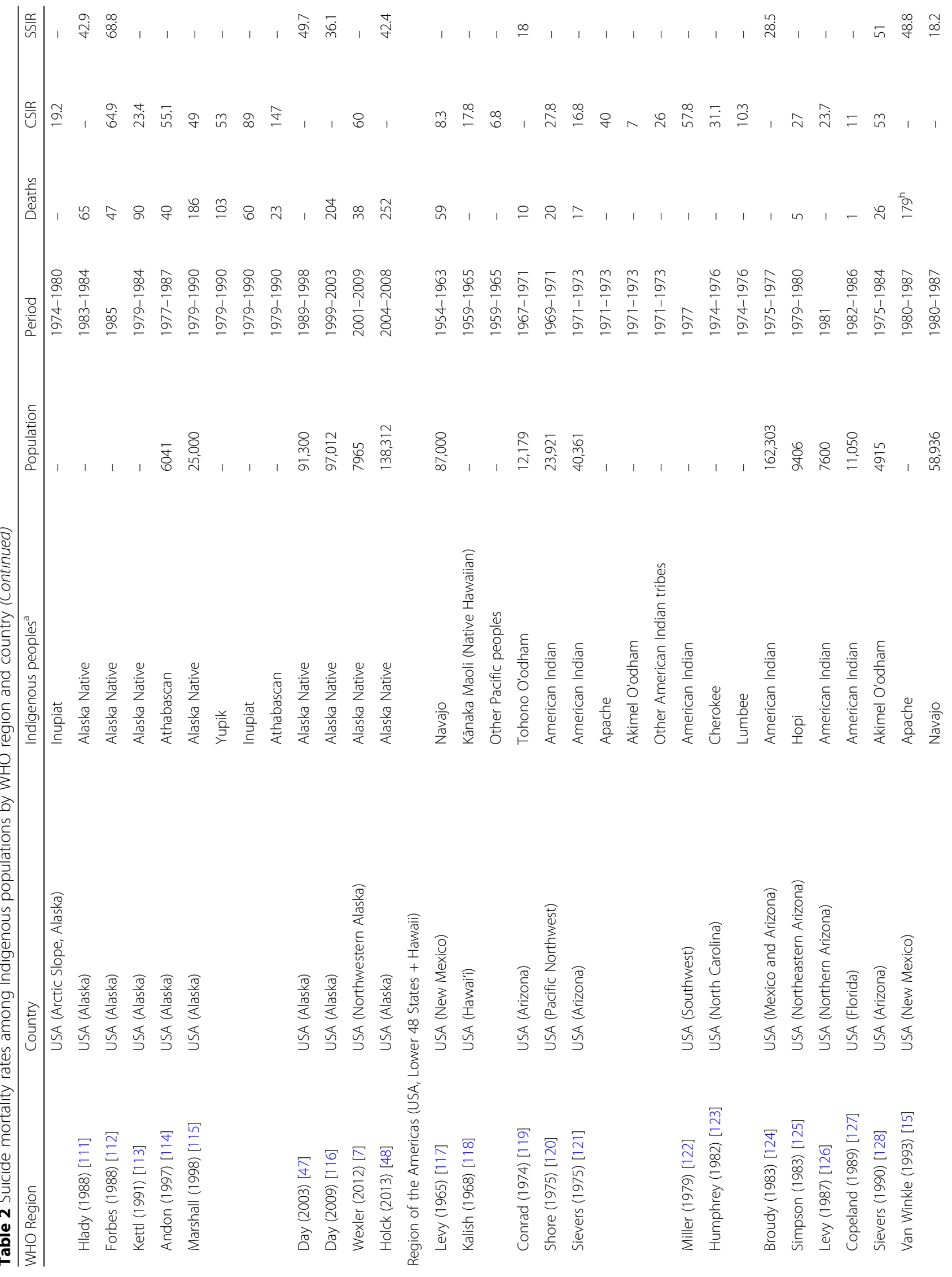


Pollock et al. BMC Medicine (2018) 16:145

Page 11 of 17

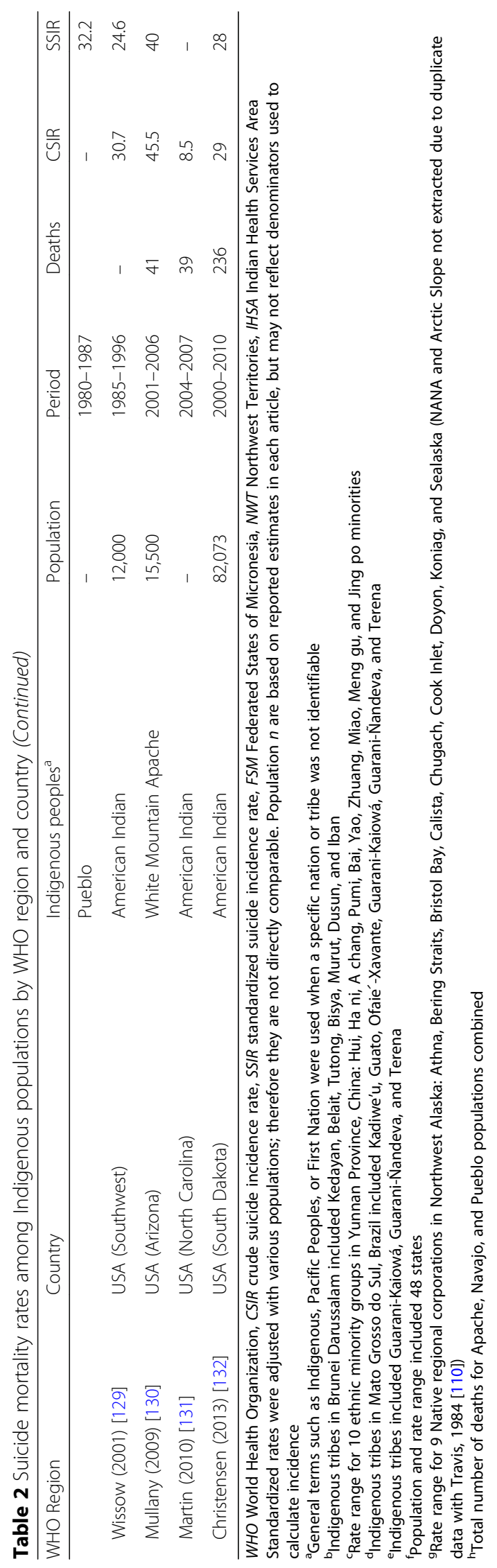


limited and conflict settings in particular, mental health services are inadequate in scope and quality, chronically under-funded, and in some places non-existent $[18,54]$.

Challenges in accessing mental health care are compounded by the limited relevance and generalizability of some "best practice" interventions in Indigenous contexts $[56,57]$. Recent clinical trials with gatekeeper training [57], hospital-based interventions [58], and mobile self-help applications [59] reported adverse and limited effects on suicide-related outcomes for Indigenous peoples. Overall, intervention studies with Indigenous populations are rare, and community-based programs are often not evaluated or have weak study designs [60-63]. These challenges point to a need to expand efforts to generate Indigenous-specific evidence [23, 56, 60]. Indeed, many communities have developed contextualized and complex approaches to suicide prevention that respond to local priorities. There is emergent evidence that such programs increase protective factors and reduce suicide-related behavior [63-65]. However, knowledge about programs' effectiveness, implementation, and capacity to scale up is limited, and many programs are not sustainably funded [56, 60-62].

Indigenous organizations and governments in New Zealand, Canada, and several Arctic states have moved beyond programmatic approaches and designed Indigenousspecific suicide prevention strategies $[23,55,66]$. These strategies integrate evidence-based public health and clinical interventions with Indigenous knowledge about the consequences of colonization, institutionalized violence and racism, and the value of culture. They also recognize that social conditions have an important role in shaping mental health, especially during the early years of life, and that improving these conditions can have a positive impact on population mental health and suicide-related outcomes. The path to lowering the incidence of suicide among Indigenous peoples and achieving health equity requires broader social transformation both within states and globally. This transformation must be collaborative, with Indigenous organizations and communities as leaders and rights-holders in knowledge production and decisionmaking $[23,29,53,56,66,67]$. Public health systems can also enhance capacity for Indigenous suicide prevention with efforts to increase the visibility of community-level differences in health status and by accurately tracking changes in suicide mortality over time.

\section{Limitations}

This study is a comprehensive synthesis of the published evidence on the global epidemiology of suicide among Indigenous peoples. Although it is the first review of this scale, our study has several important limitations. First, included studies varied their methods of identifying Indigenous populations. Self-identification is the gold standard in administrative and registry data [67]. However, this is a recent benchmark. Its uptake has varied internationally, and some countries do not identify Indigenous populations in health data at all [53, 67]. The majority of included studies relied on linkages with census or registry data, geographic proxies, or observer-determined assessments. These procedures are useful approximations, but they use varied definitions and tend to under-count Indigenous people, especially groups without legal recognition [29, 53, 67]. This can lead to ascertainment bias and underestimation of inequities [53, 67]. A second and related limitation is the under-representation of studies from low- and middle-income countries. In our review, we may have missed studies, particularly from the Global South, due to the conceptualization of Indigenous and the search terms used, which do not necessarily apply in all contexts. We attempted to limit this bias by searching databases focused on low- and middle-income countries and including non-English language papers.

The third limitation was that it was difficult to compare suicide rates between countries. Included studies were heterogeneous in population size, number of cases, aggregation, data source and outcome assessment, method of identifying Indigenous peoples, and coverage period. Many papers provided crude estimates only and did not report numerator and denominator data by age group, gender, or ethnicity. For studies with adjusted rates, different standard populations were used, and confidence intervals were rarely reported. Differences in analytic and reporting practices made it challenging to directly and reliably compare suicide rates across studies. To address this, we examined rate ratios to assess relative differences between Indigenous and non-Indigenous/general populations. This allowed us to estimate rate disparities, which were compared globally.

The fourth limitation was that studies reporting low suicide rates may be under-represented, which is a potential publication bias. It is unclear whether the lack of low incidence populations is related to the common finding of elevated rates of suicide among Indigenous peoples compared to non-Indigenous populations or, as we suspect is more likely, to the possibility that suicide rates are rarely studied when they are low. Additional low incidence reports may exist outside of peer-reviewed studies; however, these were not identified because we did not search the gray literature. The primary reason for excluding gray literature reports was the extensive volume of sources with variable quality and also the risk of over-including data from high-income nations where public reporting of mortality data is common and vital statistics infrastructure is of high quality. Nonetheless, we identified 23 papers that reported rate parity or had a rate ratio below one, but these tended to use older data. A related problem is that case studies tended to examine suicide clusters in small populations $[42,68]$. The 
a

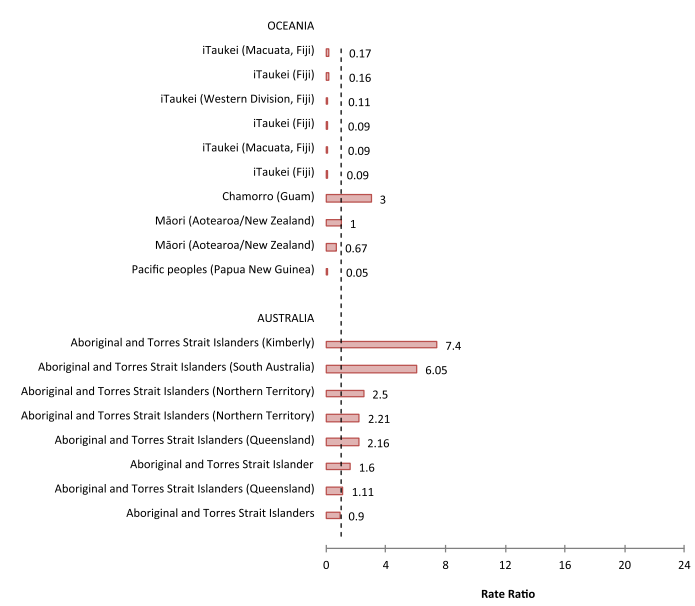

b

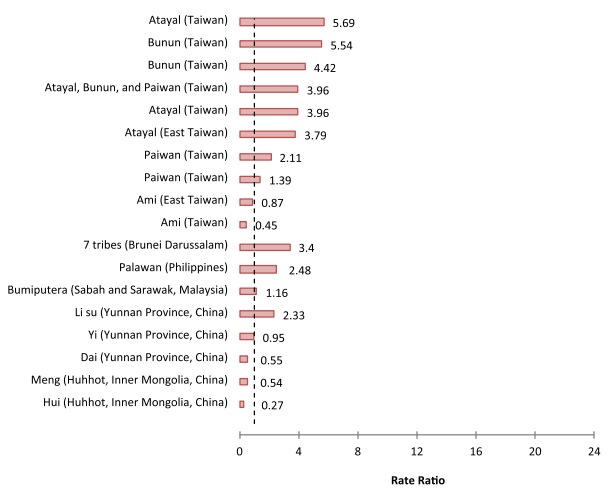

C

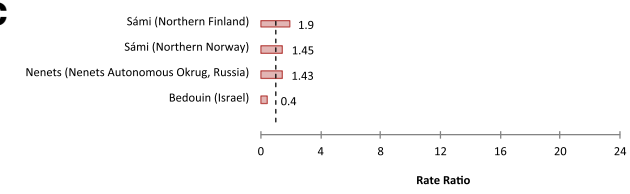

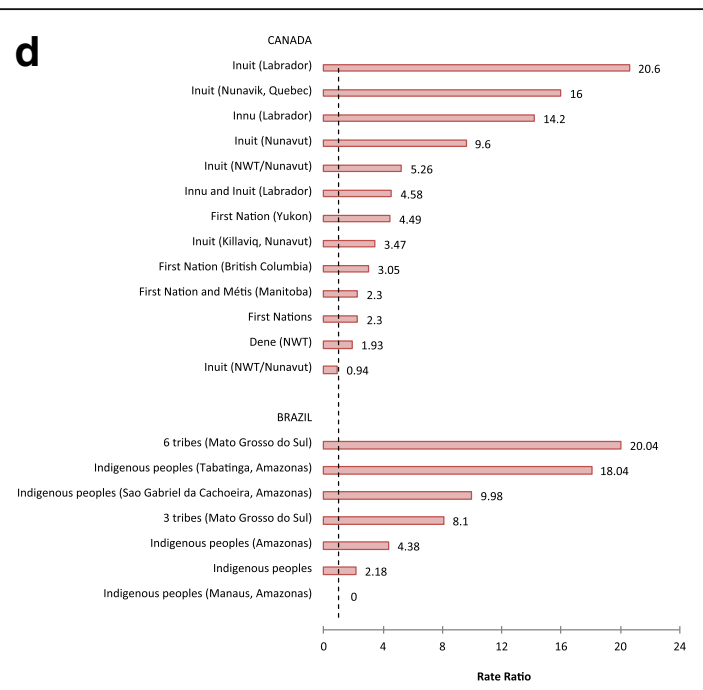

e

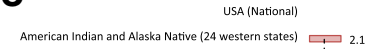

$\begin{aligned} \text { American Indian and Alaska Native } & 2.1 \\ \text { American Indian } & 1.63\end{aligned}$

American Indian and Alaska Native 12

American Indian and Alaska Native

American Indian and Alaska Native 1.01

USA (National and Regional)

American Indian and Alaska Native (Alaska IHSA) 2.45 American Indian and Alaska Native (North Plains IHSA) 209

American Indian and Alaska Native (Pacific Coast IHSA) 1.22 American Indian and Alaska Native (South Plains IHSA) 1.21 American Indian and Alaska Native (Southwest IHSA) 1.01 American Indian and Alaska Native (East IHSA) $\square: 0.73$

American Indian and Alaska Native (All IHSAS) 1.49

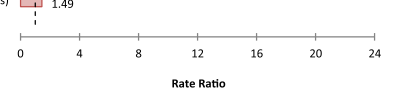

f

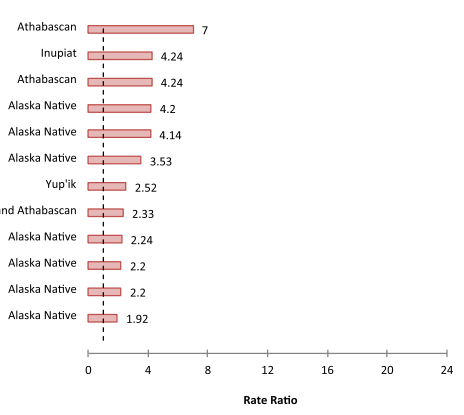

g

Akimel O'odham (Arizona) $\square 4.3$

\begin{tabular}{l:l} 
Apache (New Mexico) & 4.3 \\
\hline & 4.2
\end{tabular} White Mountain Apache (Arizona)

Cherokee (North Carolina) $\quad \begin{array}{r}3.14 \\ \hline\end{array}$

\begin{tabular}{l:l} 
Pueblo (New Mexico) & 2.8 \\
\hline & 2.8
\end{tabular}

\begin{tabular}{l:c} 
American Indian (Southwest USA) & 2.69 \\
\hline & 2.69
\end{tabular}

American Indian (South Dakota) 211 American Indian (Arizona and New Mexico) 2.3 \begin{tabular}{l:l} 
Hopi (Arizona) & 2.08 \\
\hline
\end{tabular} Navajo (New Mexico) 1.6

Kânaka Maoli (Native Hawaiian) 1.48

American Indian (Southwest)

American Indian (Arizona) 1.04

$\begin{array}{l:l}\text { Navajo (New Mexico) } & \square \\ \square & 0.72\end{array}$

Lumbee (North Carolina) $\square: 0.7$

American Indian (North Carolina) $\square: 0.59$

American Indian (Florida) $\square$

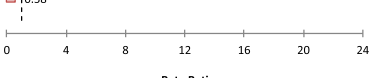

Fig. 2 (See legend on next page.) 
(See figure on previous page.)

Fig. 2 Global suicide mortality incidence rate ratios among Indigenous and comparison populations. a Western Pacific Region (Oceania and Australia). b Western Pacific Region (East Asia). c European Region. d Region of the Americas (Canada and Brazil). e Region of the Americas (USA, National). $\mathbf{f}$ Region of the Americas (USA, Alaska). $\mathbf{g}$ Region of the Americas (Lower 48 states and Hawaii). NWT Northwest Territories, IHSA Indian Health Services Area. The dotted line indicates a rate ratio of one $(\mathrm{RR}=1)$. This means that there is rate parity (no difference) between the incidence of suicide in Indigenous and comparative populations. Rate ratios to the left of the dotted line $(\mathrm{RR}<1)$ indicate that rates are comparatively higher in the non-Indigenous population. Conversely, rate ratios to the right of the dotted line $(\mathrm{RR}>1)$ show that the Indigenous population has a comparatively higher rate. Citations for each study are reported in Additional file 1: Supplement 3, Table S4

advantage of using localized data is the ability to contextualize a complex health issue. The disadvantage is that the potential to compare health status between multiple groups, across regions, and over time is reduced.

\section{Strengthening surveillance in Indigenous suicide prevention}

Our results substantiate previous work $[16,52]$ to demonstrate that elevated suicide rates are not universal among Indigenous people and debunk notions that Indigeneity increases risk for suicide. Our results also point to several gaps in knowledge about the epidemiology of suicide in Indigenous populations globally. The lack of published suicide data on Indigenous populations in low- and middle-income countries is a glaring absence. Previous studies noted a scarcity of Indigenous-specific data in the Global South overall $[18,53]$. Poor infrastructure for death registration is a key limitation [1]. In the context of suicide, this is especially problematic, because countries in Asia, Africa, and Latin and South America are the homelands for the majority of the world's Indigenous populations [18] and, at a national level, account for more than three quarters of all suicide deaths [1]. Suicide data in high-income countries tends to be of better quality than that in low- and middle-income countries; however, many governments do not include Indigenous or other ethnic identifiers in administrative health data, and do not routinely link census or Indigenous registries with national health datasets such as vital statistics. In Canada for example, the federal government does not know how many Indigenous people die by suicide in a given year. Globally, there is a critical need to strengthen capacity for surveillance in Indigenous suicide prevention.

National governments can take several steps to improve suicide surveillance in Indigenous populations. Actions should include efforts to enhance suicide data quality and standardized classification by improving vital registration infrastructure, especially in low- and middle-income countries, and integrating mortality data with monitoring of suicide attempts [1]. Countries should adopt an equitybased approach to data collection that includes Indigenous identifiers derived from self-reported sources and linked to registries or census data to address gaps in identification, and align Indigenous identification procedures with recommendations from the International Group for Indigenous Health Measurement, adapted for each national context [1, 53, 56, 67, 69]. Building inclusive, Indigenous-centered models of data governance in suicide prevention will be a critical element of strengthened surveillance. To achieve this will require national statistical agencies to not only consult Indigenous communities, organizations, and leaders about priorities, but to respect Indigenous rights to determine the parameters of data ownership, custodianship, access, and use [29, 32, 67].

Future research and global suicide surveillance efforts will be further strengthened with longitudinal and up-to-date national and state-level datasets that allow disaggregation and comparisons of outcomes in small areas and subpopulations by ethnicity $[1,17,53,56]$. Overall, these actions will help maintain robust public health surveillance systems in order to monitor health status, increase knowledge about the social determinants of suicide, target interventions, and evaluate strategies aimed at reducing the incidence of suicide among Indigenous peoples worldwide $[1,56]$. Increasing the visibility of populations that bear the greatest burden from suicide can help drive efforts to achieve the WHO and Sustainable Development Goals of reducing national suicide rates by up to $30 \%[1,69]$.

\section{Conclusions}

Suicide among Indigenous peoples is not a universal or intractable problem. Our study showed substantial global rate variation, with striking disparities in some countries. Efforts to understand these differences and to continue to build the knowledge base for effective interventions will require sustained political and financial investments in Indigenous communities, health systems, and governments. Across sectors and countries, Indigenous peoples have called for suicide prevention strategies that are community-led, strengths-based, and trauma-informed, and that redress intersecting forms of structural discrimination, social inequity, and their downstream consequences. Global efforts to reduce suicide rates among Indigenous peoples must include actions focused on communities that experience the most profound disparities, while also seeking to promote population mental health and improve health equity. 


\section{Additional file}

Additional file 1: Supplements 1-4 (Study Protocol, Methods, Results, and PRISMA Checklist). (DOCX 595 kb)

\section{Abbreviations}

Cl: Confidence interval; CSIR: Crude suicide incidence rate; FSM: Federated States of Micronesia; IHSA: Indian Health Services Area (USA);

NWT: Northwest Territories (Canada); SSIR: Standardized suicide incidence rate; UN: United Nations; USA: United States of America; WHO: World Health Organization

\section{Acknowledgements}

Work on this study was conducted while the authors resided in communities in Newfoundland and Labrador, Canada situated on the homelands of the Innu, Inuit, Mi'kmaq, and Beothuk peoples, and in communities in Ontario, Canada situated on the traditional and unceded territory of the Algonquin Nation. We respectfully acknowledge their ancestral and continued ties to the lands and waters.

We wish to thank the health science librarians who contributed their expertise to the design of this study: Janice Linton, University of Manitoba; Lindsay Alcock, Memorial University; and Lindsey Sikora, University of Ottawa. Thank you as well to our colleagues who assisted with translation, data extraction, and article access, and provided feedback on previous versions of this manuscript: Dr. Marina Sokolova, University of Ottawa; Dr. Albert Formanek, Laval University; Dr. Joseph Murray, University of Pelotas; Dr. Peter Bjerregaard, University of Southern Denmark; Dr. Yanqing Yi, Memorial University; Christopher Penney, Indigenous and Northern Affairs Canada, Government of Canada; Dr. Joyce Law, Labrador-Grenfell Health; Michele Wood, Department of Health and Social Development, Nunatsiavut Government; and Morgon Mills, Labrador Institute, Memorial University. We also recognize and are grateful for ongoing partnerships and research collaborations with the Nunatsiavut Government, Innu Nation, NunatuKavut Community Council, and LabradorGrenfell Regional Health Authority, and for administrative support from the Labrador Institute and Faculty of Medicine at Memorial University, and the University of Ottawa.

\section{Funding}

NJP was supported by doctoral scholarships from the Canadian Institutes of Health Research and is a research associate at the Labrador Institute of Memorial University with salary funding from the Government of Canada's Atlantic Canada Opportunities Agency. KN was supported by a studentship from the Ontario Mental Health Foundation. IC is an associate professor at the University of Ottawa and received salary support through the Canada Research Chairs program. SM is a professor in the Faculty of Medicine at Memorial University. There was no direct funding source for this study. All authors had full access to all the data in the study, take responsibility for the integrity and accuracy of the data, and had the final responsibility for the decision to submit for publication.

\section{Availability of data and materials}

All data relevant to this study has been reported in the manuscript or included in the additional file.

\section{Authors' contributions}

NJP, KN, AL, SM, and IC met the International Committee of Medical Journa Editors criteria for authorship, and no individual who met these criteria was excluded. NJP, IC, KN, SM, and AL conceived and designed the review; NJP and $\mathrm{KN}$ conducted the searches and screened titles and abstracts; NJP, IC $\mathrm{KN}$, and SM reviewed full text articles; AL, NJP, and KN extracted and cleaned the data; NP and IC analyzed the data; and NJP and IC planned and drafted the manuscript. All authors interpreted the results, revised the manuscript, and approved the final version of the article. NJP is the guarantor.

\section{Competing interests}

The authors declare that they have no competing interests.

\section{Publisher's Note}

Springer Nature remains neutral with regard to jurisdictional claims in published maps and institutional affiliations.

\section{Author details}

${ }^{1}$ Division of Community Health and Humanities, Faculty of Medicine, Memorial University, Prince Philip Drive, St. John's, Newfoundland and Labrador A1B 3V6, Canada. 'Labrador Institute of Memorial University, P.O. Box 490, Stn. B, 219 Hamilton River Road, Happy Valley-Goose Bay, ,Newfoundland and Labrador AOP 1E0, Canada. ${ }^{3}$ School of Epidemiology and Public Health, Faculty of Medicine, University of Ottawa, 600 Peter Morand Cr, Room 308C, Ottawa, ON K1G 5Z3, Canada.

Received: 17 January 2018 Accepted: 2 July 2018

Published online: 20 August 2018

\section{References}

1. World Health Organization. Preventing suicide: A global imperative; 2014. http://www.who.int/mental_health/suicide-prevention/world_report_2014/ en/. Accessed 17 Nov 2017.

2. Patton GC, Coffey C, Sawyer SM, et al. Global patterns of mortality in young people: a systematic analysis of population health data. Lancet. 2009: 374(9693):881-92.

3. Pridmore S, Fujiyama H. Suicide in the Northern Territory, 2001-2006. Aust N Z J Psychiatry. 2009;43(12):1126-30.

4. De Leo D, Sveticic J, Milner A. Suicide in Indigenous people in Queensland, Australia: trends and methods, 1994-2007. Aust N Z J Psychiatry. 2011;45(7):532-8.

5. Beautrais AL, Fergusson DM. Indigenous suicide in New Zealand. Arch Suicide Res. 2006;10(2):159-68.

6. Herne MA, Bartholomew ML, Weahkee RL. Suicide mortality among American Indians and Alaska Natives, 1999-2009. Am J Public Health. 2014; 104(S3):S336-42.

7. Wexler L, Silveira ML. Bertone-Johnson E. Factors associated with Alaska Native fatal and nonfatal suicidal behaviors 2001-2009: trends and implications for prevention. Arch Suicide Res. 2012;16(4):273-86.

8. Macaulay A, Orr P, Macdonald S, et al. Mortality in the Kivalliq Region of Nunavut, 1987-1996. Int J Circumpolar Health. 2004;63(Suppl 2):80-5.

9. Kirmayer $\amalg$. Suicide among Canadian Aboriginal peoples. Transcult Psychiatry. 1994;31(1):3-58.

10. Mao Y, Moloughney BW, Semenciw RM, Morrison HI. Indian reserve and registered Indian mortality in Canada. Can J Public Health. 1992;83(5):350-3.

11. Silviken A. Prevalence of suicidal behaviour among indigenous Sámi in northern Norway. Int J Circumpolar Health. 2009;68(3):204-11.

12. Bjerregaard $P$, Larsen CVL. Time trend by region of suicides and suicidal thoughts among Greenland Inuit. Int J Circumpolar Health. 2015;74 https:// doi.org/10.3402/ijch.v74.26053.

13. Hassler S, Johansson R, Sjölander P, Grönberg H, Damber L. Causes of death in the Sámi population of Sweden, 1961-2000. Int J Epidemiol. 2005:34(3):623-9.

14. Soininen L, Pukkala E. Mortality of the Sámi in northern Finland 1979-2005. Int J Circumpolar Health. 2008;67(1):43-55.

15. Van Winkle N, May PA. An update on American Indian suicide in New Mexico, 1980-1987. Hum Organ. 1993;52(3):304-15

16. Chandler MJ, Lalonde C. Cultural continuity as a hedge against suicide in Canada's First Nations. Transcultural Psychiatry. 1998;35(2):191-219.

17. Gracey M, King M. Indigenous health part 1: determinants and disease patterns. Lancet. 2009;374(9683):65-75.

18. United Nations Department of Economic and Social Development. State of the world's Indigenous Peoples: indigenous people's access to health services, 2015. http://www.un.org/esa/socdev/unpfii/documents/2016/ Docs-updates/The-State-of-The-Worlds-Indigenous-Peoples-2-WEB.pdf. Accessed 13 June 2017

19. Kirmayer $L$, Brass GM, Tait CL. The mental health of Aboriginal peoples: transformations of identity and community. Can J Psychiatr. 2000;45(7): 607-16

20. Truth and Reconciliation Commission of Canada. Honouring the truth, reconciling for the future: Summary of the final report of the Truth and Reconciliation Commission of Canada, 2015. http://www.trc.ca/websites/ trcinstitution/File/2015/Findings/Exec_Summary_2015 05 31 web_o.pdf. Accessed 17 November 2017 
21. Orellana JD, Balieiro AA, Fonseca FR, Basta PC, Souza ML. Spatial-temporal trends and risk of suicide in Central Brazil: an ecological study contrasting indigenous and non-indigenous populations. Rev Bras Psiquiatr. 2016;38(3): 222-30.

22. McQuaid RJ, Bombay A, Mclnnis OA, Humeny C, Matheson K, Anisman H. Suicide Ideation and Attempts among First Nations Peoples Living OnReserve in Canada: The Intergenerational and Cumulative Effects of Indian Residential Schools. Can J Psy. 2017;62(6):422-30.

23. Inuit Tapiriit Kanatami. National Inuit Suicide Prevention Strategy. Ottawa: Inuit Tapiriit Kanatami; 2016. https://www.itk.ca/wp-content/uploads/2016/ 07/ITK-National-Inuit-Suicide-Prevention-Strategy-2016.pdf. Accessed 17 Nov 2017

24. Lehti V, Niemelä S, Hoven C, Mandell D, Sourander A. Mental health, substance use and suicidal behaviour among young indigenous people in the Arctic: a systematic review. Soc Sci Med. 2009:69(8):1194-203.

25. Harder HG, Rash J, Holyk T, Jovel E, Harder K. Indigenous Youth Suicide: A Systematic Review of the Literature. Pimatisiwin. 2012;10(1):125.

26. Hunter E, Harvey D. Indigenous suicide in Australia, New Zealand, Canada and the United States. Emerg Med. 2002;14(1):14-23.

27. Else IRN, Andrade NN, Nahulu LB. Suicide and suicidal-related behaviors among indigenous Pacific Islanders in the United States. Death Stud. 2007; 31(5):479-501.

28. Kue Young T, Revich B, Soininen L. Suicide in circumpolar regions: an introduction and overview. Inter J Circu Health. 2015;74(1):27349.

29. Smylie JK, Firestone M. Back to the basics: identifying and addressing underlying challenges in achieving high quality and relevant health statistics for Indigenous populations in Canada. Statistical J IAOS. 2015;31(1): 67-87.

30. Pollock NJ, Mulay S, Valcour J, Jong M. Suicide rates in Aboriginal communities in Labrador, Canada. Am J Public Health. 2016;106(7):1309-15.

31. Moher D, Liberati A, Tetzlaff J, Altman DG, The PRISMA Group. Preferred Reporting Items for Systematic Reviews and Meta-Analyses: the PRISMA statement. PLoS Med. 2009;6(7):e1000097.

32. Bramley D, Hebert $P$, Jackson $R$, Chassin M. Indigenous disparities in diseasespecific mortality, a cross-country comparison: New Zealand, Australia, Canada, and the United States. N Z Med J. 2004;117(1207):U1215.

33. Booth H. Pacific Island suicide in comparative perspective. J Biosoc Sci. 1999:31(4):433-48.

34. Stevenson MR, Wallace LDD, Harrison J, Moller J, Smith RJ. At risk in two worlds: injury mortality among indigenous people in the US and Australia, 1990-92. Aust N Z J Public Health. 1998;22(6):641-4.

35. Hezel FX. Suicide and the Micronesian family. Contemp Pac. 1989;1(1):43-74.

36. Becker TM, Samet JM, Wiggins CL, Key CR. Violent death in the west: suicide and homicide in New Mexico, 1958-1987. Suicide Life Threat Behav. 1990; 20(4):324-34

37. Bjorksten KS, Bjerregaard P, Kripke DF. Suicides in the midnight sun - a study of seasonality in suicides in West Greenland. Psychiatry Res. 2005; 133(2-3):205-13.

38. Hislop TG, Threlfall WJ, Gallagher RP, Band PR. Accidental and intentional violent deaths among British Columbia Native Indians. Can J Public Health. 1987:78(4):271-4.

39. Rubinstein DH. Epidemic suicide among Micronesian adolescents. Soc Sci Med. 1983:17(10):657-65.

40. Telisinghe PU, Colombage SM. Patterns of suicide in Brunei Darussalam and comparison with neighbouring countries in South East Asia. J Forensic Legal Med. 2014;22:16-9.

41. Measey MAL, Li SQ, Parker R, Wang Z. Suicide in the Northern Territory, 1981-2002. Med J Aust. 2006;185(6):315-9.

42. Jollant F, Malafosse A, Docto R, Macdonald C. A pocket of very high suicide rates in a non-violent, egalitarian and cooperative population of South-East Asia. Psychol Med. 2014;44(11):2323-9.

43. Ali NH, Zainun KA, Bahar N, et al. Pattern of suicides in 2009: data from the National Suicide Registry Malaysia. Asia-Pacific Psychiatry. 2014;6(2):217-25.

44. Lu J, Xiao Y, Xu X, Shi Q, Yang Y. The suicide rates in the Yunnan Province, a multi-ethnic province in southwestern China. Int J Psychiatry Med. 2013; 45(1):83-96.

45. Coloma C, Hoffman JS, Crosby A. Suicide among Guarani Kaiowa and Nandeva youth in Mato Grosso do Sul, Brazil. Arch Suicide Res. 2006;10(2):191-207.

46. Souza MLP, Orellana JDY. Inequalities in suicide mortality between Indigenous and non-Indigenous people in the state of Amazonas, Brazil. J Brasileiro de Psiquiatria. 2013;62(4):245-52.
47. Day GE, Lanier AP. Alaska Native mortality, 1979-1998. Public Health Rep. 2003;118(6):518-30.

48. Holck P, Day GE, Provost E. Mortality trends among Alaska Native people: successes and challenges. Int J Circumpolar Health. 2013;72:21185.

49. Pridmore S. Suicidal behavior in the Honiara area of the Solomon Islands. Int J Ment Health. 1997;25(4):33-8.

50. Smith D. Suicide in a remote preliterate society in the highlands of Papua New Guinea. P N Guinea Med J. 1981;24(4):242-6.

51. Price J, Karim I. Suicide in Fiji: a two year survey. Acta Psychiatr Scand. 1975;52(3):153-9

52. Van Winkle N, May P. Native American suicide in New Mexico, 1957-1979: a comparative study. Hum Organ. 1986;45(4):296-309.

53. Anderson I, Robson B, Connolly M, et al. Indigenous and tribal peoples' health (the Lancet-Lowitja Institute Global Collaboration): a population study. Lancet. 2016:388(10040):131-57.

54. Incayawar M, Bouchard L, Maldonado-Bouchard S. Living without psychiatrists in the Andes: plight and resilience of the Quichua (Inca) people. Asia-Pacific Psychiatry. 2010;2(3):119-25.

55. Sami Norwegian National Advisory Unit on Mental Health and Substance Abuse, Saami Council. Plan for suicide prevention among the Sami people in Norway, Sweden, and Finland. Norway: SANKS; 2017. http://www. saamicouncil.net/fileadmin/user_upload/Documents/Eara_dokumeanttat/ Suicide plan_EN.pdf. Accessed 17 Nov 2017

56. Wexler L, Chandler M, Gone JP, et al. Advancing suicide prevention research with rural American Indian and Alaska Native populations. Am J Public Health. 2015;105(5):891-9.

57. Sareen J, Isaak C, Bolton S-L, et al. Gatekeeper training for suicide prevention in First Nations community members: a randomized controlled trial. Depress Anxiety. 2013;30(10):1021-9.

58. Hatcher S, Coupe N, Wikiriwhi K, Durie SM, Pillai A. Te Ira Tangata: a Zelen randomised controlled trial of a culturally informed treatment compared to treatment as usual in Māori who present to hospital after self-harm. Soc Psychiatry Psychiatr Epidemiol. 2016;51(6):885-94.

59. Tighe J, Shand F, Ridani R, Mackinnon A, De La Mata N, Christensen H. Ibobbly mobile health intervention for suicide prevention in Australian Indigenous youth: a pilot randomised controlled trial. BMJ Open. 2017;7(1):e013518

60. Clifford AC, Doran CM, Tsey K. A systematic review of suicide prevention interventions targeting indigenous peoples in Australia, United States, Canada and New Zealand. BMC Public Health. 2013;13(1):463.

61. Redvers J, Bjerregaard P, Eriksen $H$, et al. A scoping review of Indigenous suicide prevention in circumpolar regions. Int J Circumpolar Health. 2015;74:27509.

62. Harlow AF, Bohanna I, Clough A. A systematic review of evaluated suicide prevention programs targeting indigenous youth. Crisis. 2014;35(5):310-21.

63. Mamakwa S, Kahan M, Kanate D, et al. Evaluation of 6 remote First Nations community-based buprenorphine programs in northwestern Ontario. Can Fam Physician. 2017;63(2):137-45

64. Cwik MF, Tingey L, Maschino A, et al. Decreases in suicide deaths and attempts linked to the White Mountain Apache suicide surveillance and prevention system, 2001-2012. Am J Public Health. 2016;106(12):2183-9.

65. Allen J, Rasmus SM, Fok CCT, Charles B, Henry D, Team Q. Multi-level cultural intervention for the prevention of suicide and alcohol use risk with Alaska Native youth: a nonrandomized comparison of treatment intensity. Prev Sci. 2018:19:174-85.

66. McClintock K, McClintock R. Hoea te waka: indigenous suicide prevention outcomes framework and evaluation processes - Part 1. J Indigenous Wellbeing - Te Mauri: Pimatisiwin. 2017;2(2):68-72.

67. Coleman C, Elias B, Lee $\mathrm{V}$, et al. International Group for Indigenous Health Measurement: recommendations for best practice for estimation of Indigenous mortality. Stat J IAOS. 2016;32:729-38.

68. Ross CA, Davis B. Suicide and parasuicide in a northern Canadian native community. Can J Psychiatr. 1986;31(4):331-4

69. World Health Organization. World Health Statistics 2016: Monitoring health for the Sustainable Development Goals 2016. http://www.who.int/gho/ publications/world health_statistics/2016/en/. Accessed 17 Nov 2017).

70. Thorslund J, Misfeldt J. On suicide statistics. Arctic Med Res. 1989;48(3): 124-30.

71. Klomek AB, Nakash O, Goldberger N, et al. Completed suicide and suicide attempts in the Arab population in Israel. Soc Psychiatry Psychiatr Epidemiol. 2016;51(6):869-76. 
72. Sumarokov YA, Brenn T, Kudryavtsev AV, Nilssen O. Suicides in the indigenous and non-indigenous populations in the Nenets Autonomous Okrug, northwestern Russia, and associated socio-demographic characteristics. Int J Circumpolar Health. 2014;73:24308.

73. Clayer JR, Czechowicz AS. Suicide with Aboriginal people in South Australia: comparison with suicide deaths in the total urban and rural populations. Med J Aust. 1991;154(10):683-5.

74. Cantor CH, Slater PJ. A regional profile of suicide in Queensland. Aust N Z J Public Health. 1997;21(2):181-6.

75. Campbell A, Chapman M, McHugh C, Sng A, Balaratnasingam S. Rising indigenous suicide rates in Kimberley and implications for suicide prevention. Australasian Psychiatry. 2016;24(6):561-4.

76. Hezel FX. Cultural patterns in Trukese suicide. Ethnology. 1984;23(3):193206.

77. Ree GH. Suicide in Macuata province, Fiji: a review of 73 cases. Pract. 1971; 207(241):669-71.

78. Haynes RH. Suicide in Fiji: a preliminary study. Br J Psychiatry. 1984;145:433-8.

79. Pridmore S, Ryan K. The influence of race and sex on the method of suicide in the western division of Fiji. Fiji Med J. 1994;20:9-12.

80. Pridmore S, Ryan K, Blizzard L. Victims of violence in Fiji. Aust N Z J Psychiatry. 1995;29(4):666-70.

81. Booth $\mathrm{H}$. The evolution of epidemic suicide on Guam: context and contagion. Suicide Life Threat Behav. 2010;40(1):1-13.

82. Langley JD, Johnston SE. Purposely self-inflicted injury resulting in death and hospitalisation in New Zealand. Community Health Stud. 1990;14(2): 190-9.

83. Langley J, Broughton J. Injury to Maori I: fatalities. N Z Med J. 2000; 113(1123):508-10.

84. Parker N, Suicide in Papua B-BB, Guinea N. Med J Aust. 1966;2(24):1125.

85. Vivili P, Finau S, Finau E. Suicide in Tonga, 1982-1997. Pac Health Dialog. 1999;6(2):211-2

86. De Leo D, Milner A, Fleischmann A, et al. The WHO START study: suicidal behaviors across different areas of the world. Crisis. 2013;34(3):156-63.

87. Wang D, Wang YT, Wang XY. Suicide in three ethnic groups in Huhhot, Inner Mongolia. Crisis. 1997;18(3):112-4.

88. Cheng TA, Hsu M. A community study of mental disorders among four Aboriginal groups in Taiwan. Psychol Med. 1992;22(1):255-63.

89. Hsieh SF, Liu BH, Pan BJ, Chang SJ, Ko YC. Mortality patterns of Taiwan Aborigines due to accidents. Kaohsiung J Med Sci. 1994;10(7):367-78.

90. Wen CP, Tsai SP, Shih YT, Chung WSI. Bridging the gap in life expectancy of the aborigines in Taiwan. Int J Epidemiol. 2004;33(2):320-7.

91. Liu IC, Liao SF, Lee WC, Kao CY, Jenkins R, Cheng ATA. A cross-ethnic comparison on incidence of suicide. Psychol Med. 2011;41(6):1213-21.

92. Machado DB. dos Santos DN. Suicide in Brazil, from 2000 to 2012. J Bras Psiquiatr. 2015;64(1):45-54.

93. Butler GC. Incidence of suicide among the ethnic groups of the Northwest Territories and Yukon Territory. Med Serv J Can. 1965;21(4):252-6.

94. Young TK. Mortality pattern of isolated Indians in northwestern Ontario: a 10-year review. Public Health Rep. 1983;98(5):467.

95. Fox J, Manitowabi D, Ward JA. An Indian community with a high suicide rate: 5 years after. Can J Psychiatr. 1984;29(5):425-7.

96. Wotton K. Mortality of Labrador Innu and Inuit, 1971-1982. In: Fortuine R, editor. Circumpolar Health 84: Proceedings of the Sixth International Symposium on Circumpolar Health; 1985 May 13-18, 1984. Anchorage: University of Washington Press; 1985. p. 139-42.

97. Spaulding JM. Recent suicide rates among ten Ojibwa Indian bands in northwestern Ontario. Omega. 1985;16(4):347-54.

98. Mao Y, Morrison H, Semenciw R, Wigle D. Mortality on Canadian Indian reserves 1977-1982. Can J Public Health. 1986:77(4):263-8.

99. Garro LC. Suicides by status Indians in Manitoba. Arctic Med Res. 1988 47(Suppl 1):590-2.

100. Malchy B, Enns MW, Young TK, Cox BJ. Suicide among Manitoba's aboriginal people, 1988 to 1994. Can Med Assoc J. 1997;156(8):1133-8.

101. Isaacs S, Keogh S, Menard C, Hockin J. Suicide in the Northwest Territories: a descriptive review. Chronic Dis Can. 1998;19(4):152-6.

102. Penney C, Bobet E, Guimond E, Senécal S. Effect of community-level factors on suicide in Inuit Nunangat. Can Divers. 2009;7(3):77-84.

103. Ogden M, Spector MI, Hill CA Jr. Suicides and homicides among Indians. Public Health Rep. 1970;85(1):75-80.

104. Young TJ, French LA. Suicide and social status among Native Americans. Psychol Rep. 1993;73(2):461-2.
105. Lester D. Differences in the epidemiology of suicide in Asian Americans by nation of origin. Omega. 1994;29(2):89-93.

106. Lester D. Social correlates of American Indian suicide and homicide rates. Am Indian Alsk Native Ment Health Res. 1995:6(3):46-55.

107. Howard G, Peace F, Howard VJ. The contributions of selected diseases to disparities in death rates and years of life lost for racial/ethnic minorities in the United States, 1999-2010. Prev Chronic Dis. 2014;11:E129.

108. Kraus RF, Buffler PA. Sociocultural stress and the American native in Alaska: an analysis of changing patterns of psychiatric illness and alcohol abuse among Alaska natives. Cult Med Psychiatry. 1979;3(2):111-51.

109. Travis R. Suicide in Northwest Alaska. White Cloud J Am Indian Ment Health. 1983;3(1):23-30.

110. Travis R. Suicide and economic development among the Inupiat Eskimo. White Cloud J Am Indian. Ment Health. 1984;3(3):14-21.

111. Hlady WG, Middaugh JP. Suicides in Alaska: firearms and alcohol. Am J Public Health. 1988;78(2):179-80.

112. Forbes N, Van der Hyde V. Suicide in Alaska from 1978 to 1985: updated data from state files. Am Indian Alsk Native Ment Health Res. 1988;1(3):3655.

113. Kettl PA, Bixler EO. Suicide in Alaska natives, 1979-1984. Psychiatry. 1991; 54(1):55-63.

114. Andon HB. Patterns of injury mortality among Athabascan Indians in interior Alaska 1977-1987. Am Indian Alsk Native Ment Health Res. 1997;7(3):11-33.

115. Marshall D, Soule S. Accidental deaths and suicides among Alaska natives, 1979-1994. Int J Circumpolar Health. 1998;57(Suppl 1):497-502.

116. Day GE, Provost E, Lanier AP. Alaska native mortality rates and trends. Public Health Rep. 2009;124(1):54-64.

117. Levy J. Navajo suicide. Hum Organ. 1965;24(4):308-18.

118. Kalish RA. Suicide: an ethnic comparison in Hawaii. Bull Suicidology. 1968; 1968:37-43.

119. Conrad RD, Kahn MW. An epidemiological study of suicide among the Papago Indians. Am J Psychiatr. 1974;131(1):69-72.

120. Shore JH. American Indian suicide: fact and fantasy. Psychiatry. 1975;38(1): 86-91.

121. Sievers ML, Cynamon MH, Bittker TE. Intentional isoniazid overdosage among southwestern American Indians. Am J Psychiatr. 1975;132(6):662-5.

122. Miller M. Suicides on a southwestern American Indian reservation. White Cloud J Am Indian. Ment Health. 1979;1(3):14-8.

123. Humphrey JA, Kupferer HJ. Homicide and suicide among the Cherokee and Lumbee Indians of North Carolina. Int J Soc Psychiatry. 1982;28(2):121-8.

124. Broudy DW, May PA. Demographic and epidemiologic transition among the Navajo Indians. Soc Biol. 1983;30(1):1-16.

125. Simpson SG, Reid R, Baker SP, Teret S. Injuries among the Hopi Indians: a population-based survey. J Am Med Assoc. 1983;249(14):1873-6.

126. Levy JE, Kunitz SJ. A suicide prevention program for Hopi youth. Soc Sci Med. 1987;25(8):931-40.

127. Copeland AR. Suicide among nonwhites. The metro Dade county experience, 1982-1986. Am J Forensic Med Pathol. 1989;10(1):10-3.

128. Sievers ML, Nelson RG, Bennett PH. Adverse mortality experience of a southwestern American Indian community: overall death rates and underlying causes of death in Pima Indians. J Clin Epidemiol. 1990;43(11): 1231-42.

129. Wissow LS, Walkup J, Barlow A, Reid R, Kane S. Cluster and regional influences on suicide in a southwestern American Indian tribe. Soc Sci Med. 2001;53(9):1115-24

130. Mullany B, Barlow A, Goklish N, et al. Toward understanding suicide among youths: results from the White Mountain Apache tribally mandated suicide surveillance system, 2001-2006. Am J Public Health. 2009;99(10):1840-8.

131. Martin SL, Proescholdbell S, Norwood T, Kupper LL. Suicide and homicide in North Carolina: initial findings from the North Carolina Violent Death Reporting System, 2004-2007. N C Med J. 2010;71(6):519-25.

132. Christensen M, Kightlinger L. Premature mortality patterns among American Indians in South Dakota, 2000-2010. Am J Prev Med. 2013:44(5):465-71. 